\title{
Ensino de Futsal para Pessoas com Deficiência Intelectual ${ }^{1}$ TEACHING of FUtSAL FOR INTELLECTUALLY DisABLED PEOPLE
}

\author{
Érica Roberta JOAQUIM ${ }^{2}$ \\ Luiz Eduardo Pinto Basto Tourinho DANTAS ${ }^{3}$
}

\begin{abstract}
RESUMO: este estudo teve como objetivo verificar os efeitos de um programa de ensino de Futsal para jovens e adultos com DI, centrado nas perspectivas táticas de ensino de jogos esportivos e coletivos (JEC), no desempenho das açóes de jogo. A amostra foi composta por 11 alunos com DI, com idade entre 18 e 40 anos. Foram realizadas 30 intervençóes, sendo ministradas duas aulas por semana com duraçáo de $1 \mathrm{~h} 20 \mathrm{~min}$ cada. Para análise dos dados foram realizadas filmagens de jogos formais com duração de oito minutos cada, antes e após o programa de intervenção, observando o número de execução das seguintes açôes de jogo: progressão e/ou drible, passe, finalização, opção de passe, marcação atrás da bola, marcação individual, marcação atrasada - consideradas ações positivas - e finalização rifada, passe rifado, não atacar e não marcar - consideradas açóes negativas. Como resultado, pode-se verificar que 9 alunos apresentaram maior número de açôes ao término do programa, assim como aumento no número das açóes positivas, enquanto apenas 2 alunos apresentaram frequência das açôes de jogo semelhantes antes e após as intervençôes. Como conclusão, acredita-se que um programa contextualizado nos JEC de invasão, sistematizado com base em um modelo de jogo que atenda as demandas dos alunos, abordando os conteúdos a partir das perspectivas táticas de ensino dos JEC, pode constituir um cenário bastante interessante para essa população.
\end{abstract}

PALAVRAS-CHAVE: Educação Especial. Deficiência Intelectual. Educação Física. Esporte para Deficientes.

\begin{abstract}
The purpose of this paper was to investigate the impact of a Futsal education program for young adults and adults with ID, centered on teaching tactical proposals through Collective Sports Games, on the game actions performance. The sample was composed of 11 individuals with ID, aged between 18 and 40 years. The program was conducted over 30 classes, with 2 classes per week, each lasting 1 hour and 20 minutes. For purposes of data analysis, formal games, lasting 8 minutes during preintervention and post-intervention were video recorded, observing the frequency of the following game actions: moving forward with the ball and/or dribbling, passing the ball to other teammate, kicking towards the goal, positioning in pitch so as to be an option to receive a pass, marking between the forwards and the goal, man-to-man marking, late marking - all these classified as positive actions - and kicking the ball with no direction, making a pass with no direction, not attacking and not marking - all these were classified as negative. As a result, at the end of the program, it could be noted that 9 individuals showed an increase in frequency of actions, whereas only 2 individuals showed similar frequency of actions both before and after intervention, which means an enhance in the game engagement, as well as an increased number of positive actions. In conclusion, it is believed that a program based on strategic/tactical game model that meet the individuals' demands and that address content derived from tactical viewpoints of CSGs teaching can be a rather interesting scenario for this population.
\end{abstract}

KEYWORDS: Special Education. Intelectual Disability. Physical Education. Sport for Disabled Students.

\section{INTRODUÇÃo}

Segundo a Cartilha do Censo 2010 (BRASIL, 2012) 8,3\% da população brasileira apresenta algum tipo de deficiência, sendo que $1,4 \%$ desse total apresenta, isoladamente ou em comorbidade com outras deficiências, a deficiência intelectual (DI): mais especificamente na população considerada adulta, essa porcentagem sobe para 1,6\% da população brasileira. A DI é caracterizada pelo atraso no desenvolvimento intelectual e pela dificuldade que a pessoa tem em se comunicar, em cuidar de si mesma, realizar tarefas domésticas, aprender, brincar, traba-

\footnotetext{
${ }^{1}$ http://dx.doi.org/10.1590/S1413-65382216000100008

${ }^{2}$ Mestre em Ciências pela Escola de Educação Física e Esporte, Universidade de São Paulo, São Paulo, SP, Brasil. ericajoq@yahoo.com.br ${ }^{3}$ Professor Doutor da Escola de Educação Física e Esporte, Universidade de São Paulo, São Paulo, SP, Brasil. Idantas@usp.br
} 
lhar, entre outras (BRASIL, 2012). Segundo a Associação Americana de Deficiência Intelectual e Desenvolvimento (AAIDD, 2010), a DI é entendida como "limitaçóes significativas tanto no funcionamento intelectual quanto no comportamento adaptativo, expresso por habilidades adaptativas conceituais, sociais e práticas, originando-se antes dos dezoito anos”.

Nas últimas décadas, o número e a diversidade dos programas de intervençóes para pessoas com DI, como uma forma de influenciar alguns aspectos do seu desenvolvimento, têm aumentado significativamente (AMIRALIAN, 2003). Entre os vários tipos de programas que têm demonstrado um impacto positivo sobre o desenvolvimento dessas pessoas, programas voltados para o ensino e prática de jogos esportivos coletivos (JEC) podem ser vistos como uma possibilidade.

Os JEC são fenômenos culturais de grande popularidade em nossa sociedade. Esses jogos são compostos por alguns denominadores comuns, como: a existência de um implemento esférico que pode ser lançado com as mãos ou com os pés, ou ainda com o auxilio de algum equipamento; um terreno delimitado onde se desenvolve o jogo; uma meta a alcançar e outra a defender; companheiros de equipe que contribuem com a movimentação do implemento; adversários opondo-se a sua equipe, e regras que devem ser respeitadas (BAYER, 1994). Os JEC podem ser entendidos como um confronto entre duas equipes que se dispóem pelo terreno de jogo movimentando-se de maneira particular, alternando situaçóes de ataque e defesa com o objetivo de marcar pontos e vencer (GARGANTA, 1998).

Dentre os JEC, os jogos de invasão são caracterizados pela ação simultânea de duas equipes em um terreno comum (espaço de jogo). Essa simultaneidade confere aos jogos de invasão uma alta complexidade e aleatoriedade nas relações de cooperação e oposição estabelecidas entre os jogadores, exigindo dos mesmos uma constante adaptação estratégico-tática frente às situaçôes que emergem durante o jogo (SILVA; GRECO, 2009). Para Gréhaigne e Guillon (1992), o problema fundamental dos JEC de invasão pode ser explicado da seguinte forma: em uma situação de oposição, os jogadores devem coordenar suas ações com a finalidade de conservar, recuperar e fazer progredir o implemento do jogo, tendo como objetivo criar situações de finalização para pontuar ou fazer o gol.

A lógica complexa decorrente da imprevisibilidade das situações de jogo composta pelas relaçóes de ataque e defesa, cooperação e oposição estabelecidas entre as equipes e jogadores, constituem o alicerce dos JEC de invasão. Em razão dessas relaçóes, o desafio de cada jogador encontra-se em cooperar com seus companheiros de equipe, opondo-se da melhor forma possível aos seus adversários ao atacar ou defender, adaptando-se às demandas do jogo. A intensa variabilidade de ocorrências desses jogos faz com que o domínio das técnicas da modalidade não garanta o sucesso na resolução dos problemas encontrados no jogo, tendo em vista a exigência de uma permanente adaptação diante das situaçôes que geralmente são apresentadas sob forte pressão temporal (GARGANTA, 2000).

Dessa forma, para que o ensino dos JEC de invasão seja eficaz para pessoas com DI, algumas características relacionadas ao comportamento e à etiologia dessa população devem ser consideradas, entre elas alguns aspectos físicos e motores como: alteraçóes de tônus muscular, dificuldades/deficiências no controle motor, no equilíbrio dinâmico e estático, nas orientações espaciais e temporais, na lateralidade, na manipulação de objetos e no esquema corporal geral. 
Além desses, alguns aspectos cognitivos e sociais como: falta de autonomia e iniciativa frente determinadas situaçóes, tendência a evitar o fracasso, curtos períodos de atenção, dificuldade com operaçóes abstratas e em lidar e expressar sentimentos de agrado ou desagrado, euforia ou frustração (HERNÁNDEZ et al., 1998; FERRETI, 1999; GORLA, 2004)

Assim, o simples oferecimento dessa categoria de JEC para pessoas com DI sem considerar as particularidades da populaçáo, não garante o sucesso do programa de intervenção. Em outras palavras, para que o envolvimento das pessoas com DI nos JEC resulte em um impacto positivo sobre o desenvolvimento dessas pessoas, é necessário que as características listadas acerca dessa populaçáo sejam consideradas no processo de ensino/aprendizagem de cada indivíduo, e mesmo na prática de qualquer JEC.

Este estudo partiu da premissa que um programa de ensino centrado nos JEC de invasão, programa esse pautado em uma perspectiva de ensino/aprendizagem das açóes de jogo (perspectiva tática), pode contribuir com o desenvolvimento de pessoas com DI dentro da modalidade escolhida, além de proporcionar a aquisição de uma atividade de lazer que pode ser usufruída ao longo da vida.

De acordo com as perspectivas táticas de ensino dos JEC, a compreensão tática do jogo é o foco principal do processo de ensino/aprendizagem, visto que a maneira como atua um jogador depende de como o mesmo concebe o jogo. Essa percepção orienta as respectivas decisōes e a compreensão das informaçóes, otimizando a organização da percepção e a resposta motora frente a um problema (GARGANTA, 1998). Os autores adeptos dessa perspectiva, como Mahlo (1970), Bayer (1979), Bunker e Thorp (1982), Greco (2007) e Graça, Ricardo e Pinto (2007) atribuem grande importância ao processo de tomada de decisão para a realização de açóes inteligentes, enfatizando a necessidade de reflexóes acerca das açóes de jogo e situaçóes que emergem durante a prática.

As propostas táticas, de maneira geral, utilizam os jogos modificados como representação dinâmica do jogo formal. As orientações de Bayer (1979) ilustram as semelhanças entre as propostas de ensino dos JEC baseadas em uma perspectiva tática, ou inspirados em uma concepção de jogo em que a dimensão estratégico-tática é o que define esse tipo de prática corporal. O autor preconiza que o ensino dos JEC deve ser estruturado pelo princípio da continuidade (relaçáo do novo com o antigo), da progressáo (apoiando-se em aprendizagens anteriores) e complexidade crescente (desafios relacionados à forma como a atividade é concebida em sua estrutura e organizaçáo), e que a modificação dos jogos seja realizada com o objetivo de acentuar determinados elementos, a fim de favorecer o desenvolvimento de gestos técnicos, comportamentos e conhecimentos táticos desejados.

Assim, este estudo teve como objetivo verificar o efeito de um programa de ensino de Futsal para jovens e adultos com DI, centrado nas perspectivas táticas de ensino dos JEC, no desempenho das açóes de jogo. 


\section{Metodologia}

\subsection{Proposta Pedagógica para DeSenVolvimento do Programa de ENSINO}

As propostas de Mahlo (1970), Bayer (1979), Bunker e Thorp (1982), Greco (2007) e Graça, Ricardo e Pinto (2007), que caracterizam uma perspectiva tática de ensino dos JEC, foram utilizadas como base teórica para o desenvolvimento do programa de ensino.

\subsubsection{DesenVolVimento do PROGRAMA}

O programa de ensino foi desenvolvido por um período de quatro meses, sendo ministradas duas aulas por semana, cada uma com duraçâo de 1 hora e 20 minutos, totalizando 30 intervençóes. A amostra do estudo foi composta por 11 alunos com deficiência intelectual, com idade entre 18 e 40 anos, todos inscritos no programa denominado "futsal especial" realizado no Centro de Práticas Esportivas da USP (CEPEUSP).

Em um primeiro momento foram realizadas reunióes com os responsáveis pelos participantes do estudo a fim de esclarecer os objetivos e métodos que seriam utilizados para o desenvolvimento do programa. Posteriormente, um termo de consentimento livre e esclarecido (TCLE) foi distribuído e assinado pelos responsáveis, autorizando a participação dos alunos na pesquisa que foi aprovada pelo Comitê de Ética para pesquisas com seres humanos da Universidade de São Paulo, com o protocolo número 02712712.6.0000.5391.

Após esta primeira etapa, foram realizadas observaçōes de jogos de futsal dessa população, com a intençáo de identificar o nível do grupo estudado e realizar uma projeção dos objetivos gerais e conteúdos a serem trabalhados. A partir dessa observação, uma árvore de decisão foi elaborada, constituindo o alicerce do programa de intervenção (JOAQUIM, 2013).

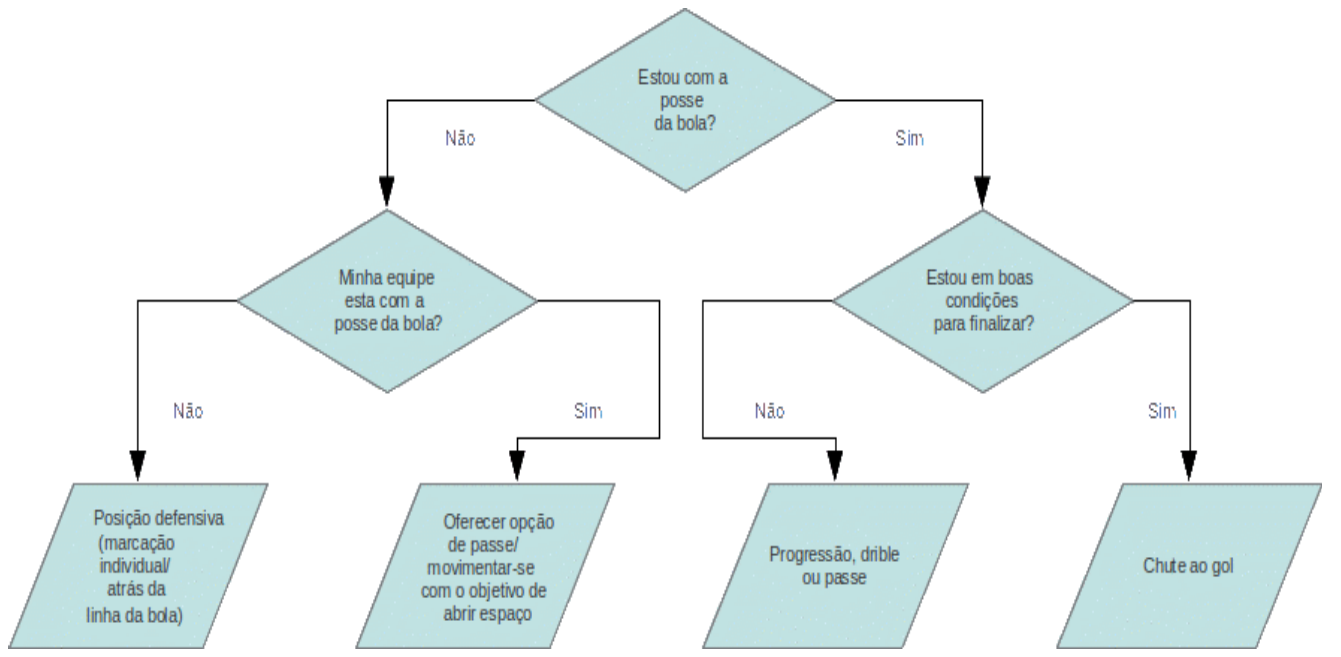

Figura 1 - Árvore de decisão.

Fonte: (JOAQUIM, 2013). 
Além de uma diretriz/orientação para as tomadas de decisóes básicas do jogo, no último nível da árvore de decisão são apresentadas algumas possíveis açóes de jogo ótimas (ações táticas) para a solução dos problemas enfrentados. Em razão da complexidade do jogo de futsal, algumas ações além das apresentadas na árvore de decisão emergiram no decorrer do processo de ensino. Essas açóes foram classificadas de acordo com o critério de adequação ao jogo, em açóes positivas e açóes negativas buscando abarcar as açóes que predominaram nas observaçóes dos jogos formais dessa população. Assim, foram denominadas açóes positivas as que contribuíram para o desenvolvimento do jogo, como: progredir com a bola e/ou driblar, realizar o passe, finalizar, oferecer opção de passe, marcação atrás da linha da bola, marcação individual e marcação atrasada, e como açóes negativas as que não contribuíram para o bom desenvolvimento do jogo (açóes que pausam o jogo em demasia, ou que potencialmente não permitam que o jogador tenha sucesso de acordo com a lógica e as regras do jogo), como: finalização rifada, realizar o passe rifado, não realizar ação de ataque e não realizar ação de marcação (JOAQUIM, 2013).

A classificação das ações em positivas e negativas é válida apenas para a população deste estudo, uma vez que foram realizadas observaçóes longas e criteriosas (antes do programa de ensino) a respeito das açóes que emergiam durante as aulas e de como essas açóes afetavam o desenvolvimento do jogo. As açóes aqui classificadas como negativas poderiam ser consideradas positivas em determinadas situaçóes de jogo e para determinadas populaçóes (mesmo pessoas com DI). Assim, a seleção e a adequação das ações devem ser realizadas de acordo com o grupo que participará do programa de ensino.

A seguir, serão apresentados o conceito, as estratégias e os critérios utilizados para a avaliação de cada ação de jogo selecionada.

\section{AÇÓES POSITIVAS}

1) Progredir com a bola elou driblar: ação de conduzir a bola até um momento de jogo adequado a outra execução motora, incluindo pequenos dribles e desvios de adversário, e/ou drible sob pressão (quando o jogador permanece protegendo a bola de seus adversários por alguns segundos do jogo, movimentando-se com a intenção de encontrar uma melhor opção de ação).

Estratégia: analisar o espaço e progredir com a bola quando não estiver sob pressão, ou mesmo driblar um oponente com o objetivo de se aproximar da meta ou ficar em melhor posiçáo para executar outra ação.

Critérios para avaliação: a progressão com bola e os pequenos dribles ou desvios de adversários durante uma posse de bola foram contabilizados como apenas uma ação, no entanto o drible sob pressão foi contabilizado separadamente. Exemplo: um jogador progride dominando a bola por alguns metros, onde encontra uma oposição iniciando um drible sob pressão. Nesse caso foram contabilizadas duas açóes. Foram consideradas as açóes realizadas com sucesso e também com insucesso. $\mathrm{O}$ ato de receber a bola e movimentá-la levemente apenas com a intenção de deixá-la em uma posição confortável para executar outra ação de jogo, não foi caracterizado como uma progressão ou drible. 
2) Realizar o passe: ação de direcionar a bola para um companheiro de equipe.

Estratégias: analisar o jogo (levantar a cabeça) e direcionar a bola a um companheiro em melhores condiçóes.

Critérios para avaliação: para a ação de passar a bola para um companheiro de equipe, não foram contabilizadas as cobranças de lateral e também o início do jogo no centro da quadra. Foram consideradas as ações realizadas com sucesso e também com insucesso.

3) Oferecer opção de passe: ação de movimentar-se para apoiar o jogador que se encontra com a posse da bola.

Estratégias: buscar linha de passe, correr para o espaço vazio, procurar receber em uma posição mais favorável, fugir do campo visual do marcador, infiltrar se não houver pressão na bola, aproximar-se de seu companheiro se a bola estiver pressionada.

Critérios para avaliação: foram consideradas as movimentações e mudanças de posições em quadra realizadas pelo jogador com a intenção de receber a bola. Se o mesmo recebeu a bola duas vezes movimentando-se apenas uma, foi contabilizada apenas uma ação de opção de passe. Caminhadas curtas em paralelo ao companheiro de equipe com a posse da bola, também foram contabilizadas como apenas uma ação de opção de passe. As aproximações em direção ao goleiro com a intenção de receber a bola, oferecendo linha de passe, mesmo que o deslocamento do jogador tenha sido reduzido, foram consideradas opção de passe. As ações em que o jogador se movimentou, no entanto claramente não ficou desmarcado, em boas condiçóes para receber a bola, não foram contabilizadas. Também não foram contabilizadas as situações em que o jogador esteve em boas condiçôes para receber a bola, mas não posicionou o corpo de forma a demonstrar intenção em recebê-la.

4) Finalizar: ação de chutar a bola em direção ao gol.

Estratégias: analisar e selecionar a melhor oportunidade de finalizar, olhar para a meta e equilibrar o corpo a fim de marcar o gol.

Critérios para avaliação: foram consideradas como finalizaçôes realizadas com sucesso aquelas em que o jogador intencionalmente chuta a bola na direção do gol, sem oposição próxima e direta, independentemente de realizá-lo.

5) Marcação individual: ação de acompanhar e marcar um jogador até que se troque de marcação ou termine o lance.

Estratégias: acompanhar o adversário buscando dificultar a progressão do mesmo, fechar linha de passe, não permitir que o adversário fique em uma posição favorável para receber a bola, ou mesmo tentar roubar a bola com uma ação rápida (dar um bote).

Critérios para avaliação: se um jogador da equipe defensiva realiza durante uma ação coletiva de ataque de seu adversário marcação individual rápida (bote) em dois ou mais jogadores consecutivamente, foi considerada apenas uma ação de marcação. No entanto se houver um intervalo entre tais marcaçóes individuais, devido à movimentação da equipe adversária, 
foi considerado o número de marcações (botes) realizadas pelos jogadores de defesa. Também foram contabilizadas as açóes em que o jogador de defesa acompanhou um mesmo adversário durante toda uma jogada.

6) Marcação atrás da linha da bola: ação de posicionar-se atrás da linha da bola visando impedir a progressão da equipe adversária.

Estratégias: analisar o posicionamento da bola e da equipe adversária, com o objetivo de fechar os espaços do modo mais eficiente possível.

Critérios para avaliação: ao permanecer atrás da linha da bola durante todo o ataque adversário foi contabilizada apenas uma ação, no entanto, se a bola e o ataque adversário ultrapassaram a linha do jogador e o mesmo retomou a marcação atrás da linha da bola, mais uma ação foi somada, o mesmo procedimento foi realizado nos casos em que o jogador passou a marcar individualmente ou mesmo tenha deixado de realizar a ação de marcar durante o ataque adversário. Em todos os reinícios de jogo realizados pela linha lateral e/ou linha central da quadra foi observada a posição dos jogadores, contabilizando uma ação caso ele tenha permanecido atrás da linha da bola de maneira a dificultar a ação do ataque adversário. Nas situações em que o jogador se posicionou atrás da linha da bola e o ataque adversário iniciou, mas não teve continuidade até se aproximar da posição do jogador observado, foram contabilizadas como ação de marcação atrás da linha da bola. Todavia, se o jogador se posicionou atrás da linha da bola, porém de uma maneira que não ofereceu oposição (não permaneceu fechando linha de passe ou ocupando o espaço de forma a dificultar a movimentação e o acesso ao gol pela equipe adversária), não foram contabilizadas como ação de marcação atrás da linha da bola.

7) Marcação atrasada: ação atrasada de tentar posicionar-se atrás da linha da bola, ou mesmo de marcar um adversário individualmente, logo após o início da ação coletiva de ataque de seus adversários. A marcaçáo atrasada foi classificada como uma ação positiva, pois o fato de o jogador perceber que deve efetuar a marcação mesmo que isso ocorra de forma atrasada e inadequada, é algo positivo para a população estudada, que tende a evitar situaçóes em que possam resultar em frustraçóes.

Estratégias: analisar o posicionamento da bola e dos adversários, iniciando uma ação de marcação após o inicio do ataque adversário, caracterizando um atraso na ação em razão do ataque adversário.

Critérios para avaliação: foram contabilizadas as açóes em que o jogador da equipe em fase defensiva, após o inicio do ataque, passou a correr em direção ao adversário com a intenção de dificultar a açáo do atacante aproximando-se do jogador com a posse da bola dificultando sua ação mesmo que indiretamente.

\section{AÇÖES NEGATIVAS}

1) Realizar o passe rifado: ação de passar a bola sem conferir-lhe direção adequada. inadequada.

Estratégia: análise inadequada da situação de jogo e seleção de ação ou direção 
Critérios para avaliação: foram contabilizadas as ações em que o jogador com a posse da bola não conferiu direção à mesma ao realizar um passe, tocando a bola com força e direção inadequada.

2) Finalização rifada: ação de chutar a bola sem direcioná-la à meta.

Estratégia: análise inadequada da situação de jogo realizada sem olhar para a meta, finalizando sem direção adequada, ou com oposição muito próxima e direta.

Critérios para avaliação: foram contabilizadas as ações em que o jogador com a posse da bola realizou um chute ao gol sem conferir-lhe direção, ou mesmo sob oposição próxima e direta.

3) Não realizar ação de ataque: situações em que o jogador permanece parado ou movimentando-se aleatoriamente na quadra de ataque ou defesa, não realizando açóes que venham a contribuir com o ataque de sua equipe.

Critérios para avaliação: foram contabilizadas as situações em que o jogador permaneceu parado ou movimentando-se aleatoriamente na quadra de ataque ou defesa, não realizando açóes que a contribuíram com o ataque de sua equipe. Contudo, caso sua equipe tenha recuperado a bola e realizado um contra-ataque rápido, no qual nitidamente o jogador de ataque observado náo conseguiria se aproximar para participar da jogada, permanecendo fora da jogada, não foram contabilizados como não realiza ação de ataque.

\section{4) Não realizar ação de marcação}

Critérios para avaliação: o jogador permanece parado ou movimentando-se aleatoriamente na quadra de ataque ou defesa, não oferecendo oposição ao adversário.

\subsubsection{DesENVOLVIMENTo DAS AULAS}

As sessões de treinamento foram compostas por três fases: aquecimento com duração de 20 minutos, parte principal com duração de 40 minutos e parte final com duração de aproximadamente 20 minutos.

$\mathrm{Na}$ fase de aquecimento as atividades propostas consistiram de tarefas simplificadas, em que o principal foco constituiu-se de ações individuais:

- Tarefas baseadas no jogo: Atividades propostas com o objetivo de trabalhar dificuldades específicas dos alunos, relativas à execução das açóes de jogo, como o controle da bola, o domínio, a progressão, o passe para um companheiro mais bem posicionado e o posicionamento durante a fase defensiva. Nestas tarefas as soluções foram bastante facilitadas, reduzindo a pressão sobre o jogador com a posse da bola, aumentando as possibilidades de açôes corretas, para garantir que as açôes com a posse de bola fossem ensinadas.

A parte principal foi constituída por jogos modificados (regras, configuração das equipes, restrição de espaços) que envolveram tarefas de cooperação e oposição: 
- Formas básicas do jogo: Jogo formal adaptado às competências do grupo, sendo preservados os elementos essenciais do jogo formal, como a igualdade numérica, a forma de pontuar e a conversão natural do ataque em defesa e da defesa em ataque. Por exemplo: goleiro $+2 \mathrm{X}$ $2+$ goleiro ou goleiro +3 X $3+$ goleiro.

- Formas parciais de jogo: Jogos modificados com o objetivo de trabalhar as dificuldades particulares dos alunos em relação a algumas ações de jogo (finalizar, impedir a finalização, progredir, impedir a progressão, entre outras) ou fases do jogo (com a posse de bola e sem a posse de bola, transiçóes). Por exemplo, jogos $1 \mathrm{X} 1+$ goleiro; 2 X 1 + goleiro; 3 X 2 + goleiro; goleiro +4 X $2+$ goleiro; goleiro +4 (2coringas) $\mathrm{X} 2+$ goleiro; goleiro $+2+$ apoio $\mathrm{X}$ apoio + 2 + goleiro; goleiro + 3 X 3 + goleiro + coringa (GRAÇA; RICARDO; PINTO, 2007).

A parte final das aulas foram compostas por jogos formais, em que os alunos eram frequentemente orientados e questionados quanto às açóes de jogo, recebendo feedback positivo ao realizarem as açóes adequadas às demandas.

\subsection{Procedimentos E instrumentos para aValiaÇão das aÇóes de JOGO}

As avaliações referentes às açóes de jogo foram realizadas com base na análise de vídeos dos jogos formais gravados antes do início do programa de intervenção e após o mesmo. Foram realizadas filmagens de jogos formais antes e após o programa de ensino com duração de 12 minutos cada, sendo os dois primeiros minutos e os dois últimos minutos dos vídeos descartados, totalizando oito minutos por jogo para análise. Para avaliação dos alunos foi utilizada a primeira (antes do programa) e a última (após o programa de ensino) filmagem de cada participante. Durante as filmagens os alunos receberam apenas informaçôes referentes a qual das equipes estaria com a posse da bola.

Após gravados, os jogos foram digitalizados utilizando um software específico de análise (LONGOMATCH, 2012), em que as açóes de jogo foram codificadas em eventos de forma manual sendo quantificados os eventos executados. Cada jogador foi avaliado individualmente e os registros foram realizados a partir da observaçáo das açóes de jogo de um jogador por vez.

\subsection{INSTRUMENTO DE AVALIAÇÁO: TESTE DE FIDEDIGNIDADE}

A fidedignidade do instrumento de avaliação foi verificada mediante concordância entre observadores e intraobservadores, por meio das avaliaçóes de três pesquisadores com experiência no ensino do futsal. O coeficiente de correlação intraclasse (ICC) (THOMAS; NELSON, 2002) para os dados interobservadores foi de 0,90 indicando uma forte correlação. As avaliaçóes para a concordância intra-observadores foi realizada com intervalo de dois meses entre uma avaliação e outra, e o ICC foi de 0,91 indicando também forte correlação.

\subsection{Procedimentos estatísticos}

Para a realização da análise descritiva as ações foram observadas isoladamente, e também em grupos denominados Classes de ações. Os dados foram organizados segundo o critério de adequação da ação em açóes positivas e açóes negativas, conforme descrito a seguir: 
- Passe: realizar passe (positiva) e realizar passe "rifado" (negativa).

- Finalização: finalizar (positiva) e finalização "rifada" (negativa).

- Marcação: marcação atrás da linha da bola (positiva), marcação individual (positiva), marcação atrasada (positiva) e não realiza ação de marcação (negativa).

- Movimentação: progredir com a bola e/ou driblar (positiva), oferecer opção de passe (positiva) e não realiza ação de ataque (negativa).

Dessa forma, apresentaremos as diferenças de desempenho dos alunos nas avaliaçóes inicial e final quanto às açôes no jogo de futsal.

\section{Resultados}

Mediante as tabelas e gráficos apresentados a seguir, observa-se que os participantes deste estudo apresentaram diferenças na quantidade de realizaçóes das açóes de jogo, comparando-se as açóes avaliadas antes do programa de ensino e após as intervençóes.

Tabela 1 - Ações de jogo.

\begin{tabular}{|c|c|c|c|c|c|c|c|c|c|c|c|c|c|c|c|c|c|c|c|c|c|c|c|c|}
\hline \multirow{3}{*}{$\begin{array}{l}\text { Alunos } \\
\text { Presença } \\
\end{array}$} & \multicolumn{2}{|c|}{1} & \multicolumn{2}{|c|}{2} & \multicolumn{2}{|c|}{3} & \multicolumn{2}{|c|}{4} & \multicolumn{2}{|c|}{5} & \multicolumn{2}{|c|}{6} & \multicolumn{2}{|c|}{7} & \multicolumn{2}{|c|}{8} & \multicolumn{2}{|c|}{9} & \multicolumn{2}{|c|}{10} & \multicolumn{2}{|c|}{11} & \multicolumn{2}{|c|}{ Total } \\
\hline & \multicolumn{2}{|c|}{17} & \multicolumn{2}{|c|}{19} & \multicolumn{2}{|c|}{20} & \multicolumn{2}{|c|}{16} & \multicolumn{2}{|c|}{26} & \multicolumn{2}{|c|}{30} & \multicolumn{2}{|c|}{23} & \multicolumn{2}{|c|}{15} & \multicolumn{2}{|c|}{18} & \multicolumn{2}{|c|}{18} & \multicolumn{2}{|c|}{22} & \multicolumn{2}{|c|}{30 aulas } \\
\hline & $\mathrm{I}$ & $\mathrm{F}$ & $\mathrm{I}$ & $\mathrm{F}$ & $\mathrm{I}$ & $\mathrm{F}$ & $\mathrm{I}$ & $\mathrm{F}$ & I & $\mathrm{F}$ & I & $\mathrm{F}$ & $\mathrm{I}$ & $F$ & I & $\mathrm{F}$ & $\mathrm{I}$ & $\mathrm{F}$ & I & $\mathrm{F}$ & $\mathrm{I}$ & $\mathrm{F}$ & I & $\mathbf{F}$ \\
\hline $\begin{array}{l}\text { Progredir } \\
\text { driblar }\end{array}$ & 0 & 0 & 2 & 3 & 0 & 0 & 0 & 0 & 4 & 4 & 2 & 2 & 0 & 2 & 1 & 1 & 0 & 0 & 0 & 0 & 2 & 2 & 11 & 14 \\
\hline Passar & 2 & 3 & 3 & 4 & 1 & 4 & 2 & 3 & 5 & 8 & 4 & 6 & 5 & 3 & 3 & 6 & 2 & 4 & 2 & 2 & 10 & 7 & 39 & 50 \\
\hline Finalizar & 0 & 1 & 2 & 3 & 0 & 3 & 0 & 0 & 2 & 3 & 2 & 2 & 1 & 3 & 4 & 1 & 0 & 0 & 0 & 0 & 1 & 0 & 12 & 16 \\
\hline $\begin{array}{l}\text { Opçáo de } \\
\text { passe }\end{array}$ & 8 & 16 & 9 & 16 & 7 & 14 & 6 & 8 & 12 & 9 & 12 & 12 & 11 & 9 & 14 & 13 & 8 & 10 & 7 & 9 & 14 & 13 & 108 & 129 \\
\hline $\begin{array}{l}\text { Marcaçáo } \\
\text { atrás }\end{array}$ & 6 & 9 & 10 & 6 & 9 & 9 & 1 & 7 & 8 & 7 & 7 & 13 & 8 & 11 & 9 & 9 & 1 & 8 & 1 & 4 & 7 & 12 & 59 & 95 \\
\hline $\begin{array}{l}\text { Marcação } \\
\text { indivi- } \\
\text { dual }\end{array}$ & 1 & 2 & 4 & 6 & 7 & 5 & 0 & 0 & 5 & 2 & 3 & 3 & 2 & 4 & 2 & 6 & 0 & 0 & 0 & 0 & 7 & 4 & 31 & 32 \\
\hline $\begin{array}{l}\text { Marcação } \\
\text { atrasada }\end{array}$ & 0 & 5 & 0 & 0 & 0 & 1 & 0 & 1 & 1 & 0 & 1 & 0 & 0 & 0 & 0 & 0 & 0 & 2 & 0 & 2 & 0 & 0 & 2 & 11 \\
\hline $\begin{array}{l}\text { Finalizar } \\
\text { rifado }\end{array}$ & 0 & 0 & 0 & 0 & 0 & 1 & 0 & 0 & 0 & 1 & 2 & 0 & 0 & 0 & 0 & 1 & 0 & 0 & 0 & 0 & 0 & 0 & 2 & 3 \\
\hline $\begin{array}{l}\text { Passe } \\
\text { rifado }\end{array}$ & 0 & 0 & 0 & 0 & 0 & 1 & 0 & 0 & 0 & 0 & 1 & 0 & 0 & 0 & 0 & 1 & 0 & 0 & 1 & 3 & 0 & 0 & 2 & 5 \\
\hline $\begin{array}{l}\text { Não } \\
\text { atacar }\end{array}$ & 0 & 1 & 0 & 0 & 0 & 0 & 5 & 2 & 0 & 0 & 0 & 0 & 0 & 0 & 0 & 0 & 1 & 0 & 6 & 5 & 0 & 1 & 5 & 9 \\
\hline $\begin{array}{l}\text { Náo } \\
\text { marcar }\end{array}$ & 6 & 0 & 0 & 3 & 2 & 0 & 8 & 5 & 4 & 3 & 2 & 2 & 5 & 4 & 6 & 4 & 10 & 8 & 11 & 10 & 0 & 2 & 54 & 41 \\
\hline Total & 23 & 32 & 30 & 41 & 24 & 38 & 22 & 26 & 41 & 37 & 36 & 40 & 32 & 36 & 39 & 42 & 22 & 32 & 28 & 35 & 41 & 41 & 325 & 405 \\
\hline
\end{tabular}

Legenda: (I) pré-intervenção, (F) pós-intervenção

Fonte: elaboração própria.

Os gráficos que seguem $(1,2,3,4,5,6,7$ e 8), fornecem dados da quantidade das açóes positivas e negativas relativas a cada classe de ação para as avaliaçóes realizadas antes e após o programa de intervenção. 


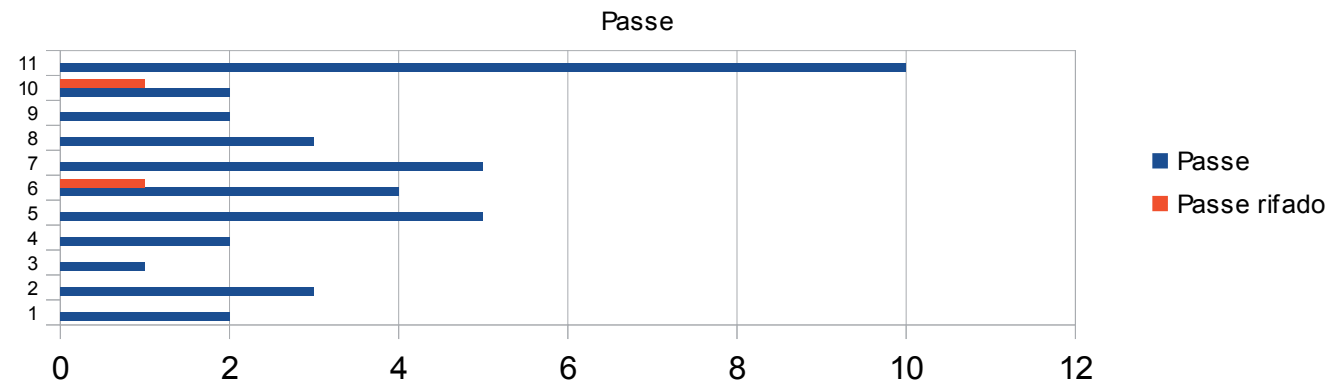

Gráfico 1 - Passe.

Fonte: elaboração própria.

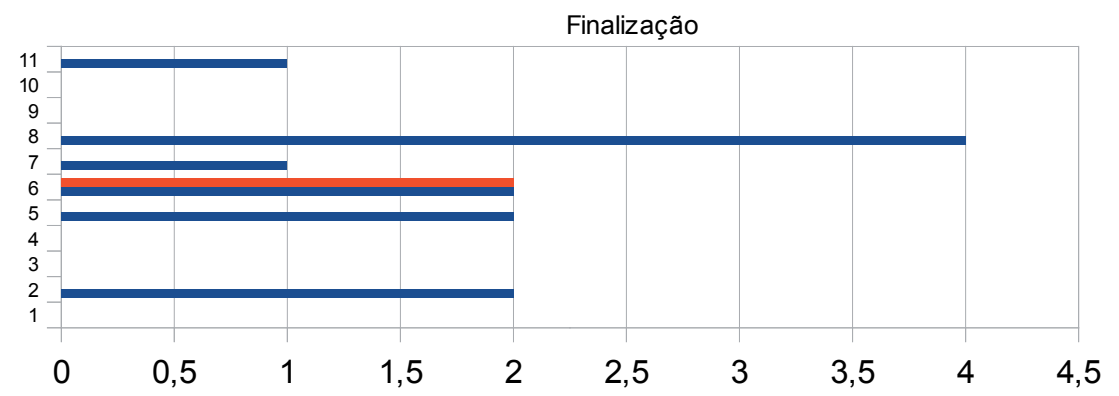

- Finalizar

- Finalizar rifado

Gráfico 2 - Finalização.

Fonte: elaboração própria.

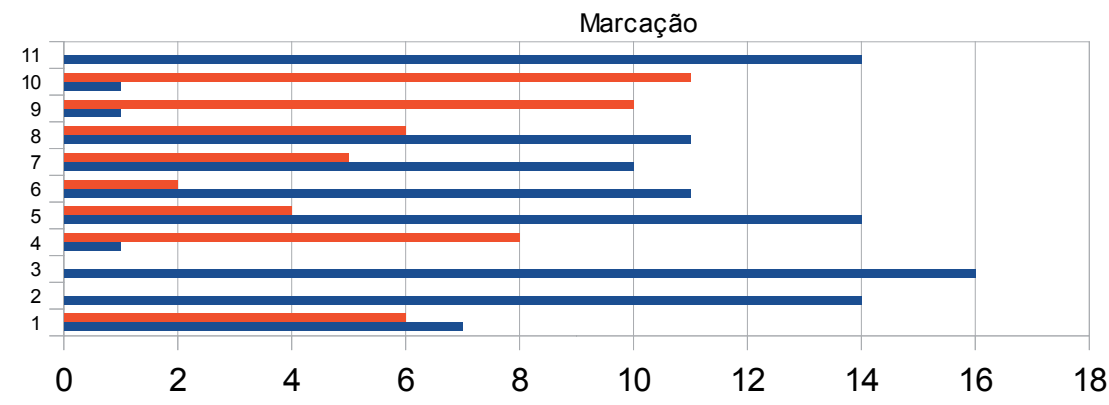

Gráfico 3 - Marcação.

Fonte: elaboração própria. 


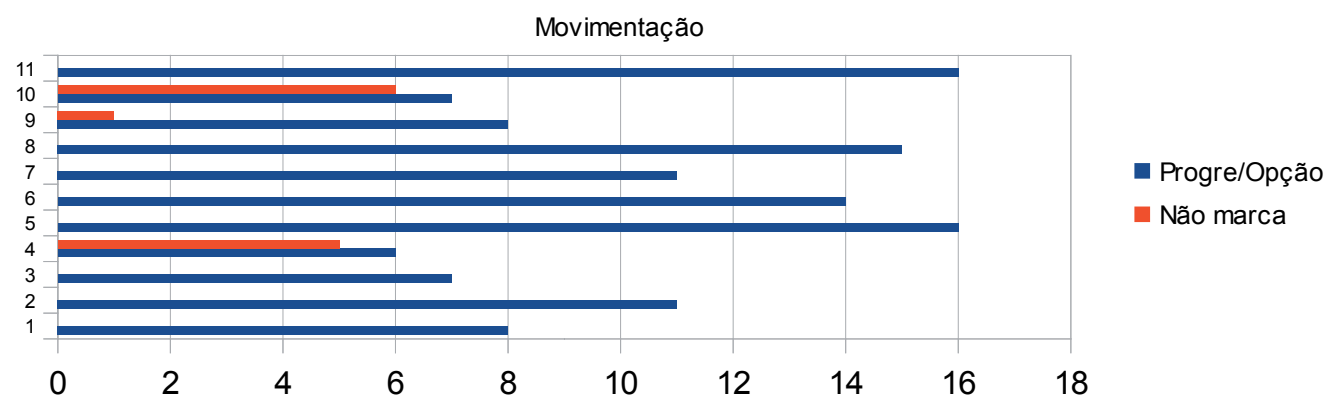

Gráfico 4 - Movimentação.

Fonte: elaboração própria.

Classes de ações: avaliação pós-intervenção

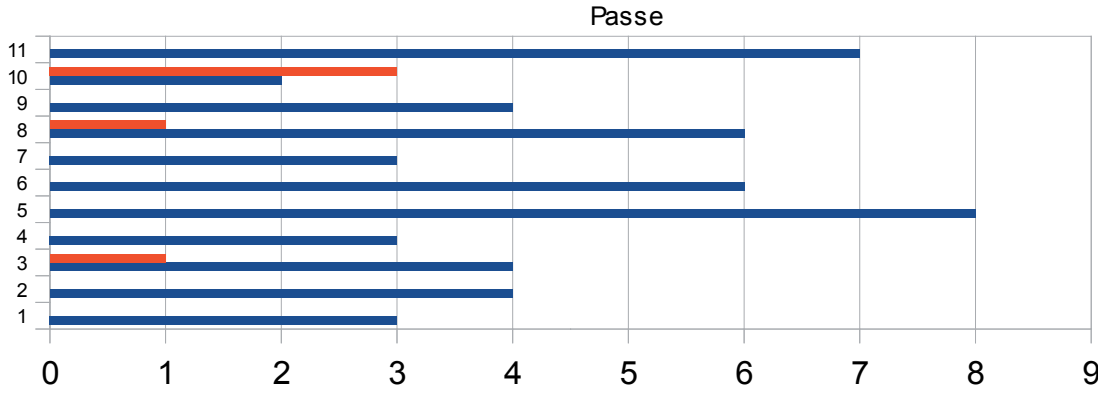

Passe

Passe rifado

Gráfico 5 - Passe.

Fonte: elaboração própria.

Finalização

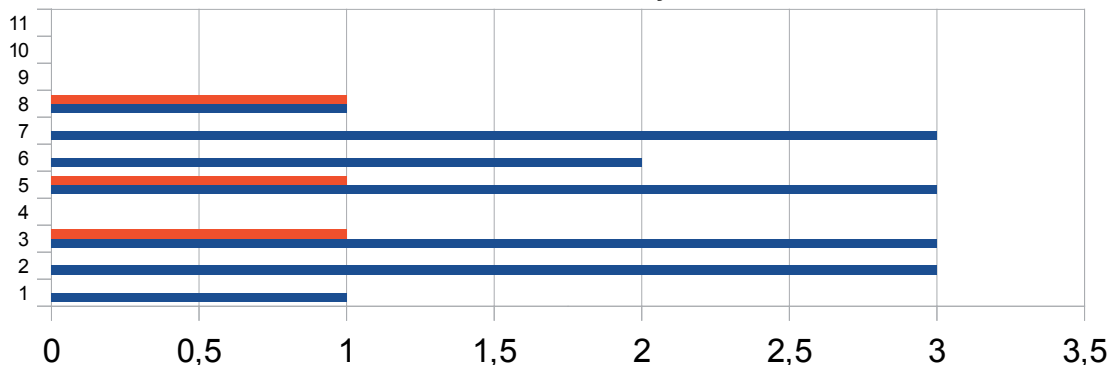

Gráfico 6 - Finalização.

Fonte: elaboração própria
- Finalizar

- Finalizar rifado 


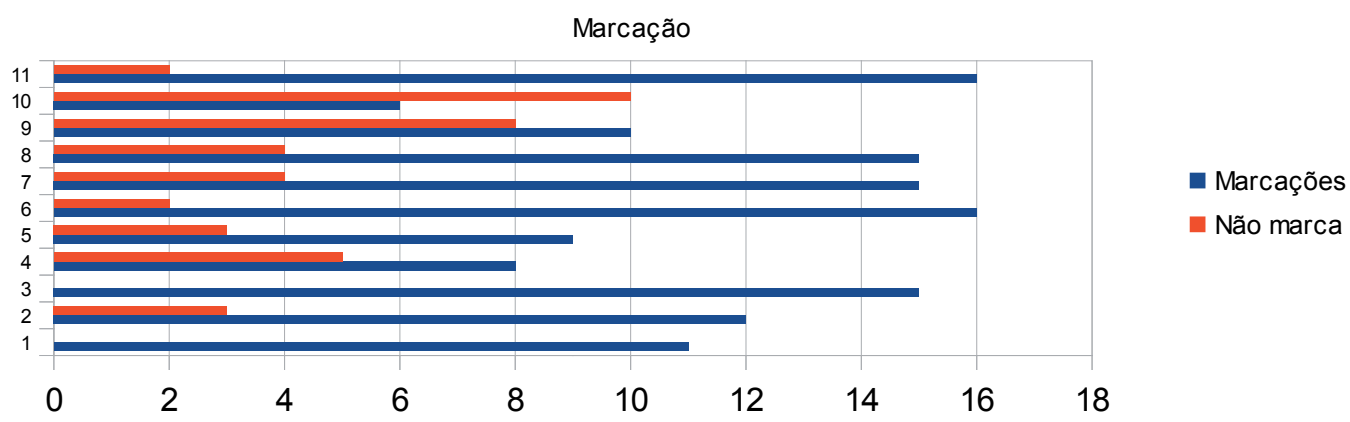

Gráfico 7 - Marcação.

Fonte: elaboração própria.

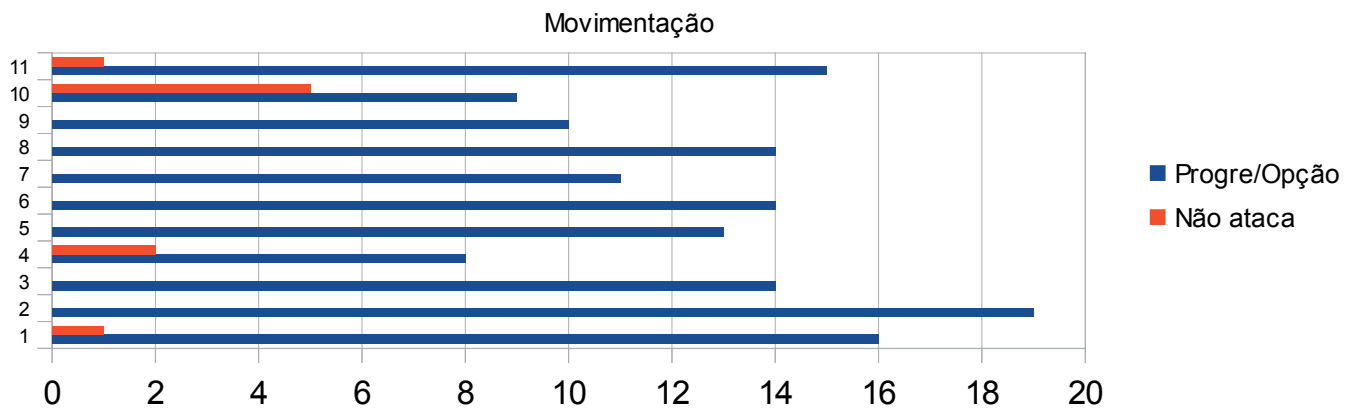

Gráfico 8 - Movimentação.

Fonte: elaboração própria.

Os dados apresentados permitem que se identifique um aumento das açóes de jogo após o programa de intervenção, tornando possível verificar que em geral os alunos apresentaram maior frequência nas ações relativas à movimentação e à marcação, porém menor frequência nas açôes de passe e finalizaçấo. Isso pode ter sido causado pelo nível de habilidade motora exigido para execução de cada ação e pelo nível de exigência do critério de avaliaçáo de cada ação, ou talvez os dois fatores "somados". As açóes de movimentação e marcação demandam principalmente habilidades de locomoçáo básicas sem a necessidade de controle do objeto. E os critérios de avaliação são relativamente fáceis de serem alcançados (exceto na ação de progredir e/ou driblar). Já as açóes de passe e finalização exigem habilidades que além de requererem um investimento razoável de tempo para serem aprendidas, demandam um nível de qualidade da execução alto para serem identificadas como uma ação positiva.

Outro ponto que deve ser considerado diz respeito à relaçáo entre o número de açóes e as características do jogo de futsal. Em razão da dinâmica do jogo e das particularidades do futsal (as regras e as dimensóes reduzidas da quadra e do gol, por exemplo), a finalização é uma ação mais difícil de ocorrer. É possível também notar que o grupo realizou maior número de 
ações após o programa de ensino, apresentando mais ações positivas, e menor número de açóes negativas, revelando melhor desempenho ao término das intervençôes.

\section{Discussáo}

Durante muito tempo os programas de intervençóes para pessoas com DI apresentaram como característica a instrução e o ensino de conteúdos sem considerar os fatores ambientais e a idade cronológica do indivíduo, buscando de certa forma "normalizar" a pessoa. Atualmente, com o princípio da autonomia permeando tal contexto, os programas para essa população têm passado por transformações importantes. A autonomia para essas pessoas supóe a utilização de habilidades intelectuais que decorrem do desenvolvimento de sua eficiência cognitiva, fundamentada na construção de conhecimentos acerca do contexto e obstáculos a serem superados a partir de suas capacidades intelectuais (MANTOAN, 1998). Assim, o presente estudo procurou romper com antigos paradigmas adotando o princípio da autonomia, respeitando a idade cronológica dos indivíduos, bem como os fatores ambientais que permearam o contexto durante o desenvolvimento do programa de ensino.

Neste estudo foi proposta uma sistematização dos conteúdos relativos ao futsal fundamentada em uma representação das decisões básicas de jogo (árvore de decisão elaborada com base na população estudada) considerando as dificuldades e potencialidades de cada indivíduo. $\mathrm{O}$ processo de ensino/aprendizagem foi pautado nas perspectivas táticas de ensino dos JEC, com o objetivo de contribuir com o envolvimento e desenvolvimento de cada participante no jogo.

A árvore de decisão, assim como as perspectivas táticas de ensino dos JEC utilizadas no decorrer do programa de ensino de futsal aplicado, possibilitou a essa população melhora no desempenho das açóes de jogo observadas, uma vez que nove alunos apresentaram aumento na frequência das açóes de jogo após o programa de ensino, e apenas dois mantiveram o desempenho semelhante ou tiveram uma pequena redução na quantidade de açóes. De maneira geral, esse "paradigma tático" contribuiu para a construção de situaçóes próximas do "jogo real”, possibilitando realizar alteraçóes na complexidade dos problemas e das respostas de acordo com o desenvolvimento do grupo, motivando um maior envolvimento do aluno e consequentemente, uma melhora no desempenho das ações de jogo.

Os resultados do presente estudo corroboram com os apresentados por Almeida (2009), indicando que as perspectivas táticas de ensino do JEC, utilizadas também para compor o programa de ensino desse estudo, podem melhorar o desempenho dessas pessoas dentro da modalidade praticada.

Com relação aos alunos 5 e 11, que apresentaram desempenhos praticamente semelhantes em suas avaliaçóes pré-intervenção e pós-intervenção, é relevante acentuar que ambos tiveram o melhor desempenho do grupo na avaliação inicial, e que estes foram normalmente os alunos que se destacaram durante as aulas em virtude do seu melhor desempenho. Provavelmente, o programa de ensino foi pouco motivante para esses alunos com desempenho superior. Por outro lado, o fato deles terem apresentado o melhor desempenho no primeiro momento, mantendo um bom desempenho no decorrer do programa, pode ter contribuído com o processo de aprendizagem das açóes de jogo dos alunos com menor desempenho, 
uma vez que na interação com seus pares esses indivíduos se reconhecem, confrontam-se e comparam-se, utilizando as ações do companheiro como referência para estabelecer seu próprio comportamento (NÁGERA, 2003).

Dessa forma, é importante refletir sobre algumas questóes relacionadas ao processo de ensino/aprendizagem dos alunos:

- A representação de jogo utilizada (árvore de decisão) como diretriz pode ter sido demasiadamente simplificada para os alunos com melhor desempenho, não permitindo que os mesmo apresentassem melhora nas avaliaçóes das açóes de jogo selecionadas após o programa?

- As execuçóes motoras das açóes de jogo deveriam ter sido avaliadas isoladamente, possibilitando intervir sobre as mesmas de maneira mais eficiente e contextualizada, o que possivelmente afetaria o desempenho das açóes de jogo avaliadas?

Essas questóes não podem ser respondidas por este estudo, sendo relevante pensar quais fatores podem ter influenciado nos resultados nele encontrados, com a finalidade de minimizar futuras dificuldades e falhas na elaboração de programas de ensino e métodos de avaliação para essa população, a qual apresenta características amplamente heterogêneas.

\section{CONSIDERAÇÓES FINAIS}

Um dos grandes desafios em propor um programa de ensino para pessoas com DI consiste em adequá-lo à diversidade da população de forma a atender as suas necessidades particulares. Um programa de ensino (considerando a dimensão motora) para essa população, contextualizado nos JEC, deve partir do interesse dos alunos na modalidade escolhida, buscando proporcionar experiências próximas do "jogo real”, adequando as demandas que podem surgir nas mais variadas situaçóes do jogo.

Este estudo teve como objetivo verificar os efeitos de um programa de ensino de Futsal para jovens e adultos com DI no desempenho das açóes de jogo, centrado nas perspectivas táticas de ensino dos JEC. Os resultados obtidos com o programa denotam que essa metodologia, amplamente utilizada e difundida para populaçóes sem deficiência, também é exequível quando aplicada para pessoas com DI e, pode-se sugerir que é eficaz para o ensino da dimensão tática do futsal. Os resultados também indicam que esse programa foi capaz de provocar mudanças no desempenho tático (açóes de jogo) de grande parte dessa amostra de pessoas com DI, o que aponta para futuras pesquisas que possam esclarecer as causas dessa melhora de desempenho e, simultaneamente, atestar a robustez desse resultado.

Outro aspecto importante a ser ressaltado está relacionado ao número das ações com a posse da bola e sem a sua posse. As açóes sem a posse da bola foi a que os alunos apresentaram maior diferença entre as avaliaçóes inicial e final. E as açóes com a posse da bola, as quais o jogador é submetido à maior pressão temporal em razão da demanda pelo próprio controle de bola, foram as ações que os alunos apresentaram menor diferença entre as avaliaçôes pré-intervenção e pós-intervenção. As respostas sem bola possibilitam "maior liberdade" para o ajuste em relação ao tempo e espaço, uma vez que a principal exigência motora nessas situaçóes é a habilidade de locomoção, sendo essas respostas predominantemente reativas (o sujeito reage às condições 
do ambiente de jogo, sendo as respostas mais simples do ponto de vista perceptivo motor). Já as ações com bola exigem habilidades manipulativas que não são triviais e tomadas de decisão rápidas para o sucesso da ação, o que demanda maior tempo e experiência para aprendizagem e aperfeiçoamento dessas açóes, sendo essas respostas predominantemente ativas (o sujeito interfere nas condiçóes do ambiente de jogo, sendo as respostas mais complexas do ponto de vista perceptivo motor). Essas diferenças entre o desempenho das açóes sem bola e com bola apontam para a importância do trabalho com as açóes técnicas durante todo o processo, porém de forma contextualizada no jogo, modificando-o de forma a acentuar os aspectos desejados.

Durante a execução do programa, puderam ser verificadas algumas alterações comportamentais dos participantes, além de alguns aspectos qualitativos relativos à sua aprendizagem, como segue:

- Os jogadores passaram a se comunicar mais de forma gestual e verbal, fato que incidiu positivamente sobre a autonomia desses alunos no contexto do jogo, visto o nível ao qual se enquadravam com relação ao jogo.

- Mediante algumas atividades propostas, em que se optou pela superioridade numérica (4 X 2; 4 X 3, entre outras), pôde-se observar que inicialmente esse fato dificultou as açóes da equipe em superioridade, o que nos leva a acreditar que quanto maior o número de elementos que o sujeito tem de considerar para tomar suas decisóes, maior sua dificuldade, mesmo que essa situação privilegie a sua equipe. Esta dificuldade foi minimizada durante o programa a partir do momento em que os alunos passaram a perceber a relação entre a sua posição e a vantagem de seu grupo.

- No decorrer do programa as exigências colocadas pela pesquisadora responsável algumas vezes foi percebida como algo negativo, e isso fez com que um dos alunos (aluno 11, com um dos melhores desempenhos iniciais) pensasse em desistir das aulas. Sua fala foi “- tá muito difícil pra mim, eu saio nervoso... náo vale a pena...”, a partir desse comentário e da convivência diária com este aluno, pode-se inferir que o mesmo tem consciência de suas limitaçóes e que o excesso de exigência fez com que isso transparecesse, deixando-o desestimulado. Nessa situação torna-se nítida a importância de saber dosar as exigências durante o programa de intervenção, problema que se acredita ter sido sanado durante este programa após tal experiência.

- As açóes relativas à fase defensiva apresentaram uma particularidade muito interessante, qual seja: alguns alunos tiveram dificuldade em compreender como efetuar a marcação atrás da linha da bola, denominada "marcação por zona". Em uma dessas situações, a instrução foi para que permanecessem na frente da bola, entre a bola e o gol; no entanto um aluno perguntou à pesquisadora: “aonde é a frente da bola, Professora?”. Nesse momento compreendeu-se a dificuldade com a abstração e com a referência para executar essa ação; assim, passou-se a fazer algumas analogias, como: ao "recheio do sanduíche" e também a uma "parede" que deve proteger o gol diante da bola. Esses recursos contribuíram bastante para a compreensão da ação. Esse fato é um alerta para a necessidade da aprendizagem ser significativa, isto é, ancorada no conhecimento prévio do aluno com DI. 
Com base nessas consideraçóes, acredita-se que alguns problemas necessitam de investigaçóes posteriores. Um aspecto relevante está relacionado à replicação da metodologia utilizada com pessoas (DI) sem experiência na modalidade, uma vez que os alunos deste estudo tinham um conhecimento prévio sobre o jogo, o que pode ter influenciado os resultados. Além disso, acredita-se na necessidade de replicação do estudo com outras amostras (diversas faixas etárias), como também na possibilidade de ampliá-lo para outras modalidades, com o intuito aprofundar o conhecimento sobre o ensino de JEC para pessoas com DI.

\section{REFERÊNCIAS}

AAIDD. American Association on Intellectual and Developmental Disabilities. Intellectual Disability: definition, classification and systems of supports. 11. ed. United States of America: The AAIDD Ad. Hoc Committee on Terminology and Classification, 2010.

AMIRALIAN, M. L. T. M. Deficiências: um novo olhar. Contribuiçóes a partir da psicanálise winnicottiana. Estilos da Clínica, v.8, n.15, p. 94-111, 2003.

BAYER, C. L'enseignement dês jeux sportifis collectis. Paris: Editora. Vigot, 1979.

BAYER, C. O ensino dos desportos colectivos. Lisboa: Editora Dinalivro, 1994.

BUNKER, D.; THORPE, R. A model of teaching games for secondary school. Bulletin of Physical Education, v.18, n.1, p.5-18, 1982.

BRASIL. Secretaria de Direitos Humanos da Presidência da República. Secretaria Nacional de Promoção dos Direitos da Pessoa com Deficiência. Cartilha do censo 2010 - Pessoas com Deficiência. Brasília, DF: SDH-PR/SNPD, 2012.

GARGANTA, J. Para uma teoria dos jogos desportivos colectivos. In: GRAÇA, A.; OLIVEIRA, J. (Org.). O ensino dos jogos desportivos. Porto: FCDEF-UP, 1998. p.11-25.

GARGANTA, J. O treino da táctica e da estratégia nos jogos desportivos: horizontes e órbitas no treino dos jogos desportivos. Porto: FCDEF-UP, 2000. p.51-61.

GRAÇA, A.; RICARDO, V.; PINTO, D. O ensino do basquetebol: aplicar o modelo de competência nos jogos de invasão criando um contexto desportivo autêntico. In: TANI, G.; BENTO, J. O.; PETERSEN, R.D.S. (Org.). Pedagogia do desporto. Rio de Janeiro: Editora Guanabara Koogan, 2007.

GRECO, P. J. Iniciação esportiva universal: metodologia de iniciação esportiva na escola e no clube. Belo Horizonte: Editora UFMG, 2007.

GRÉHAIGNE, J. E.; GUILLON, R. L'utilisation dês jeux d'opposition a 1'école. Revue de 1'Education Physique, v.32, n.2, p.51-67, 1992.

GORLA, J. I. Desempenho psicomotor em portadores de deficiência mental: avaliação e intervenção. Revista Brasileira de Ciências do Esporte, Campinas, v.25, n.3, p.133-147, 2004.

JOAQUIM, E. R. Ensino de futsal para pessoas com deficiência intelectual. 2013. 94f. Dissertação (Mestrado em Ciência) - Escola de Educação Física e Esporte, Universidade de Pão Paulo, São Paulo, 2013.

MAHLO, F. O acto tático no jogo. Lisboa: Editora Compendium, 1970.

MANTOAN, M. T. E. Educação escolar de deficientes mentais: problemas para a pesquisa e o desenvolvimento. Cadernos CEDES, Campinas, v.46, 1998. 
NÁGERA, A. V. Os adolescentes e os pais. Lisboa: Editora Presença, 2003.

SILVA, M. V.; GRECO, P. J. A influência dos métodos de ensino-aprendizagem-treinamento no desenvolvimento da inteligência e criatividade tática em atletas de futsal. Revista Brasileira de Educação Física e Esporte, São Paulo, v.23, n.3, p.297-307, 2009.

THOMAS, J. R.; NELSON, J. K. Métodos de pesquisa em atividade física. 5.ed. Porto Alegre: Editora Artmed, 2008.

Recebido em: 14/07/2015

Reformulado em: 16/03/2016

Aprovado em: 17/03/2016 